\title{
Percepção dos profissionais de saúde e dos usuários sobre o aconselhamento no teste rápido para HIV
}

\author{
Perception of health professionals and users about counseling in the context of rapid HIV testing \\ Percepción de los profesionales de salud y usuarios acerca del conseñado en el contexto de la prueba \\ rápida para VIH
}

Paula Barreto Silva Xenofonte Costa Lima ${ }^{1}$ (])

Maria Alix Leite Araújo ${ }^{1}$ (1)

Anna Karynne Melo ${ }^{1,2}$ (1)

João Marcos de Araújo Leite ${ }^{1}$ (1)

1. Universidade de Fortaleza, Pós-Graduação em Saúde Coletiva. Fortaleza, CE, Brasil.

2. Universidade de Fortaleza, Curso de graduação em Psicologia. Fortaleza, CE, Brasil.

Autor correspondente:

João Marcos de Araújo Leite

E-mail: joaomarcosleite09@gmail.com

Recebido em 23/07/2019.

Aprovado em 05/12/2019.

DOI: 10.1590/2177-9465-EAN-2019-0171

\section{RESUMO}

Objetivo: Analisar a percepção acerca do aconselhamento no contexto do teste rápido para o HIV. Método: Pesquisa com abordagem qualitativa realizada no Centro de Testagem e Aconselhamento com profissionais de saúde e com usuários do Centro de Testagem e Aconselhamento. A análise seguiu os passos propostos na fenomenologia empírica de Giorgi articulando-a com a literatura. Resultados: Identificaram-se cinco categorias: a experiência anterior à realização do Teste Rápido; Intencionalidade de sentimentos; Percepção do aconselhamento pelo usuário; Percepção do aconselhamento individual no pós-teste e; Percepção de profissionais sobre o aconselhamento. $\mathrm{O}$ aconselhamento coletivo é percebido pelos usuários como palestra sobre HIV/Aids com ênfase em consequências negativas; e o aconselhamento individual, como mais confortável e como possibilidade para exposição de dúvidas. Discussão: Considera-se que, mesmo sabendo da importância do aconselhamento, este é realizado de forma empírica, reduzindo o ato ao repasse de informações com teor educativo, visando apenas à aprendizagem cognitiva como meio de disseminar o conhecimento, tentando, assim, reduzir a cadeia de transmissão da HIV/Aids.

Palavras-chave: Aconselhamento; Doenças Sexualmente Transmissiveis; Testes Sorológicos; Sorodiagnóstico da Aids.

\section{ABSTRACT}

Objective: To recognize the perception of counseling by professionals and users of the Testing and Counseling Center to perform the Rapid Test for the diagnosis of HIV. Method: Qualitative research conducted at the Testing and Counseling Center. We interviewed users and professionals who performed the rapid test. The analysis followed the steps proposed in the empirical phenomenology of Giorgi, articulating with the literature. Results: Five categories were identified: Prepredicative experience when performing The quick test; Intent of feelings; Perception of user advice; Perception of individual counseling in the post-test and; Perception of professionals about counseling. Collective counseling is perceived by the users as a talk about STI / Aids with an emphasis on negative consequences and individual counseling as more comfortable and possibility for exposing doubts. Discussion: It is considered that even knowing the importance of counseling, this is done in an empirical way, reducing the act to the transfer of information with educational content, aiming at only cognitive learning and as a means of disseminating knowledge, thus trying to reduce the HIV/ Aids transmission chain.

Keywords: Counseling; Sexually Transmitted Diseases; Serological tests; Aids serodiagnosis.

\section{RESUMEN}

Objetivo: Analizar la percepción acerca del asesoramiento en el contexto de la prueba rápida para el VIH. Método: Investigación con enfoque cualitativo realizada en el Centro de Pruebas y Asesoramiento con profesionales de salud y de los usuarios del Centro de Pruebas y Asesoramiento. El análisis siguió los pasos propuestos en la fenomenología empírica de Giorgi, articulando con la literatura. Resultados: Se identificaron cinco categorías: la experiencia anterior a la realización de la prueba rápida; Intencionalidad de sentimientos; Percepción del asesoramiento por el usuario; Percepción del asesoramiento individual en el post-test y; Percepción de profesionales sobre el asesoramiento. El asesoramiento colectivo es percibido por los usuarios como conferencia sobre HIV / SIDA con énfasis en consecuencias negativas y el asesoramiento individual como más cómodo y posibilidad para la exposición de dudas. Discusión: Se considera que, aunque se sabe de la importancia del asesoramiento, éste se realiza de forma empírica, reduciendo el acto al traspaso de informaciones con contenido educativo, visando que el sólo el aprendizaje cognoscitivo y como medio de diseminar el conocimiento, intentando así reducir la cadena de transmisión de la HIV / SIDA.

Palabras clave: Asesoramiento; Enfermedades sexualmente transmisibles; Pruebas serológicas; Sorodiagnóstico del sida. 


\section{INTRODUÇÃO}

Apesar de todos os avanços em relação ao tratamento de pessoas que vivem com o Human Immunodeficiency Virus (HIV)/ Acquired Immune Deficiency Syndrome (Aids) ou outra infecção sexualmente transmissível (IST), acredita-se que o melhor "remédio" ainda é a prevenção.

A infecção pelo HIV ainda é grave problema de saúde pública e estimam-se, de acordo com dados do Ministério da Saúde, lançados no ano de 2018, que foram notificados pelo Sistema de Informação de Agravos de Notificação (SINAN), no ano de 2007 até 2018, 247.795 casos de infecção pelo HIV no Brasil, ocorrendo, apenas no ano de 2018, 17.248 novos casos. ${ }^{1}$ Enquanto, mundialmente, segundo dados da OMS, ocorreram 1.7 milhões de novas infecções, havendo 770.000 mortes relacionadas ao $\mathrm{HIV}^{2}{ }^{2}$

Viver com HIV/Aids ainda se configura como um desafio e, por esse motivo, a revelação de um diagnóstico positivo se apresenta como um momento delicado que faz emergir sentimentos como medo, vergonha, abandono, solidão, tristeza e ansiedade. ${ }^{2}$ Um dos principais problemas enfrentados pelas pessoas que recebem um resultado positivo para HIV é o estigma em relação à aids, ${ }^{3-5}$ o que pode afastá-las da procura pela testagem.

Na ocasião da entrega de resultado reagente, faz-se necessário que o profissional disponha tanto de um pouco mais de tempo para o aconselhamento como tenha a capacidade técnica para prestar apoio emocional, ajudando, dessa forma, a pessoa a lidar com sentimentos que, porventura, venham a emergir a partir desse resultado. Nesse contexto, o estabelecimento do diagnóstico por meio do teste rápido (TR) alterou, de maneira importante, a gestão do tempo, proporcionando uma nova dinâmica no aconselhamento e nas relações entre profissionais e usuários dos serviços. OTR tem uma metodologia simples, pois a coleta do sangue é realizada da polpa digital e o resultado se apresenta em, aproximadamente, 20 minutos. É uma estratégia que pode contribuir, consideravelmente, para melhorar o acesso ao diagnóstico do HIV, uma vez que a sua realização pode ocorrer para além das unidades de saúde, ou seja, em qualquer espaço, desde que haja uma programação. Vale salientar que o TR tem apresentado sensibilidade e precisão semelhantes ao teste padrão com amostras de sangue total. ${ }^{6-8}$

A ampliação do acesso à testagem tem sido preocupação constante do Ministério da Saúde ${ }^{9}$ desde o início da epidemia do HIV/aids, porém, estratégias vêm sendo adotadas com esse intuito. Uma delas foi a implantação dos Centros de Testagem e Aconselhamento (CTA). ${ }^{9}$ Esses serviços foram implantados no final da década de 80 e têm como finalidade disponibilizar o teste anti-HIV à população com aconselhamento pré e pós-teste. Entre outras estratégias, esses serviços atuam fazendo a mediação entre a prevenção e assistência à saúde..$^{10,11}$

A decisão em procurar o CTA já pode gerar um momento de tensão interior, pois perpassa pelo reconhecimento pessoal de vulnerabilidade à infecção pelo HIV. Diante desse cenário, objetivou-se analisar a percepção dos profissionais de saúde e das pessoas que procuram o CTA acerca do aconselhamento no contexto do teste rápido para HIV.

\section{MÉTODO}

Trata-se de um estudo descritivo, com abordagem qualitativa, que busca a compreensão intrínseca do seu objeto de análise tendo como prioridade o universo de valores, percepções, hábitos e atitudes dos sujeitos. ${ }^{12}$

Empregou-se o modelo empírico-compreensivo de Giorgi, ${ }^{13,14}$ que objetiva apreender a experiência cotidiana do homem e do modo como ela é vivenciada. Nessa perspectiva, faz-se uma reflexão a partir da consciência do pesquisador. Na tradição fenomenológica, a consciência está sempre associada, em geral, aos conceitos de intencionalidade, sentido e existência, $e$ é definida para além da relação cognitiva entre sujeito e objeto.

Neste estudo, busca-se reconhecer como o fenômeno do aconselhamento, na ocasião da realização do TR, é percebido pelos usuários e pelos profissionais, levando em conta os seus significados como função estruturante: no que as coisas significam, na forma como as pessoas organizam seus modos de vida e, também, nos seus cuidados com a saúde. ${ }^{15,16}$ É compreendendo e interpretando o significado do fenômeno que o mundo fenomenológico se mostra, explicita, aclara e desvela as estruturas cotidianas do mundo-da-vida deixando transparecer na descrição.

A Fenomenologia filosófica de Maurice Merleau-Ponty foi utilizada para pensar esse contexto, principalmente a obra Fenomenologia da Percepção ${ }^{16}$, por esta considerar a percepção enquanto conceito primordial para se compreender a experiência particular de indivíduos.

Desta forma, este estudo toma a noção de percepção como os modos particulares de apreensão da realidade que se dão, a partir de Merleau-Ponty, pautados pelo caráter ambíguo, considerando-se aqui a realidade enquanto pré-reflexiva, pois a percepção, a partir do autor, não se trata de uma ciência do mundo, nem mesmo um ato ou uma tomada de decisão deliberada. Sendo o mundo visto não como um objeto que se pode possuir, mas como um meio natural e, mais do que isso, um campo de todos os pensamentos e percepções explícitas. O filósofo trabalha a fenomenologia enquanto importante método para se considerar as realidades que, por definição, são particulares e pré-reflexivas, ou seja, se encontram anterior à reflexão do sujeito, cabendo a ele a descrição particular:

O real deve ser descrito, não construído ou constituído. Isso quer dizer que não posso assimilar a percepção às sínteses que são da ordem do juízo, dos atos ou da predicação. A cada momento, meu campo perceptivo é preenchido de reflexos, de estalidos, de impressões táteis fugazes que não posso ligar de maneira precisa ao contexto percebido e que, todavia, eu situo imediatamente no mundo, sem confundi-los nunca com minhas divagações ${ }^{16: 6}$.

A fenomenologia de Merleau-Ponty também se caracteriza pelo caráter ambíguo, pautando-se na noção de que a experiência é vivida de forma intersubjetiva, em coexistência, e 
ocorre na interseção do que é universal e particular. Com isso, sua fenomenologia se mostra relevante para reconhecermos a percepção dos profissionais e dos usuários do CTA por considerar que, apesar de tratar-se de experiências universais e corriqueiras, as percepções envolvidas, tanto dos usuários quanto de profissionais, são particulares.

O estudo foi realizado no CTA do município de Fortaleza/Ceará, que realiza o TR para sífilis, HIV, Hepatite B e C, por se diferenciar dos demais serviços que ofertam oTR e por ser específico para essa atividade. Na ocasião da oferta do TR, os usuários têm a oportunidade de receber o aconselhamento coletivo, bem como duas seções de aconselhamento individual (uma pré e outra pós-teste), em que são ofertadas orientações, apoio emocional e avaliação das vulnerabilidades/riscos. ${ }^{9} \mathrm{O}$ CTA conta com uma equipe de seis profissionais (assistentes sociais e enfermeiros) extremamente capacitados e experientes em aconselhamento, além de um técnico de laboratório.

Vinte e oito pessoas participaram do estudo (22 profissionais de saúde e 6 usuários) do CTA. Para os usuários, os critérios de inclusão foram ter mais de 18 anos e estar realizando pela primeira vez o TR; e, para os profissionais, foram realizar o TR e o aconselhamento. Excluíram-se as pessoas que possuíam diagnóstico médico de transtorno psicológico ou psiquiátrico, menores de 18 anos, gestantes e aqueles que já conheciam o diagnóstico de HIV.

A coleta de dados ocorreu durante o mês de dezembro de 2017 por meio de entrevista individual norteada a partir de uma questão gerativa: "Como você percebe o aconselhamento aqui no CTA para a realização do teste rápido?". Isso permitiu ao participante a liberdade de falar e atribuir significados mediante a escuta ativa do pesquisador, produzindo, assim, respostas que precisaram ser posteriormente codificadas. Ressalta-se que os usuários foram abordados em dois momentos: após o aconselhamento coletivo e após realizarem o aconselhamento individual; já os profissionais, estes foram entrevistados no final do expediente da manhã ou da tarde, conforme combinado previamente.

As entrevistas foram transcritas na íntegra e a análise ocorreu de acordo com o método de Giorgi, com inspiração fenomenológica, o qual tem como objetivo principal investigar em detalhes, a experiência dos participantes e o modo como estes Ihe dão sentido. Assim, a interpretação ocorre por meio de duas perspectivas: como o participante dá sentido para as suas experiências e como o pesquisador dá sentido para a significação deste sujeito.

O estudo foi aprovado pelo Comitê de Ética em Pesquisa da Universidade de Fortaleza - UNIFOR com parecer de número 76611617.6.0000.5052. Como se tratava de explanar acerca da atividade de aconselhamento realizada no serviço, as entrevistas foram efetivadas em um espaço privativo, e os participantes foram identificados pela letra $(U)$ de usuário $e$ (P) de profissional, seguido de algarismo arábico em sequência de entrevista concedida.

\section{RESULTADOS}

Como a relação ao sexo dos usuários que realizaram o TR, a grande maioria $(68,1 \%$ ) era composta de mulheres; com relação à idade, houve variação de 18 a 50 anos (média de 30,0); já em relação à cor/raça, $78,6 \%$ se autodeclaram pardos e $21,4 \%$ brancos. Em relação à escolaridade, $68,2 \%$ haviam concluído o ensino médio, $22,7 \%$ se encontravam cursando o ensino superior e $9,1 \%$ possuíam ensino fundamental.

No que concerne à caracterização dos profissionais, todas são do sexo feminino: $50 \%$ eram assistentes sociais e 50\% enfermeiras, cujas idades variavam de 27 a 50 anos (média de 34,8), e a grande maioria $(66,7 \%)$ se autodeclarou parda.

De posse dos discursos transcritos na íntegra, foram realizadas várias leituras e releituras no intuito de garantir totalidade das descrições, assim como capturar o sentido dos discursos em uma visão geral do fenômeno que é manifestado, e aproximar-se da experiência vivenciada pelos participantes do estudo. Destarte, buscou-se identificar unidades convergentes, divergentes e transformantes, enquadrando, em conjuntos e subconjuntos, as expressões significativas para a compreensão do fenômeno em questão e daí emergir as unidades de significação. Por meio da síntese das unidades de significação sob a forma de projeção concisa do fenômeno revelado, procurou-se a interpretação do arcabouço do fenômeno. Desta forma, as unidades de significados foram agregadas, originando cinco categorias: Experiência anterior à realização do TR; Intencionalidade de sentimentos; Percepção do aconselhamento pelo usuário; Percepção do aconselhamento individual no pós-teste e; Percepção dos profissionais sobre o aconselhamento.

\section{DISCUSSÃO}

\section{Experiência anterior à realização do TR}

Esta unidade de significação apresenta os discursos cuja narrativa se inicia com as caraterísticas do trajeto até a realização do TR, como 'estilo de vida' ou 'comportamento de risco', solicitação médica ou inquietação pessoal, ou parceiro com receio de conviver ou ser diagnosticado com a doença. O estilo de vida e comportamento de risco foram os motivos apontados pelos usuários ao buscarem realizar o TR.

[...] estar aqui é uma consequência das minhas ações [...] Mas descobri que um ex-boy meu tá (HIV), então vim. (U09).

Tava tendo relações casuais com um rapaz e a camisinha furou, e descobri que ele também tem relações com outra pessoa, que tem outra pessoa! Quando descobri meu mundo caiu, pensei no risco que corro (os olhos cheios de lágrima) (U10).

Já outros usuários acessaram o serviço, por conta própria, movidos por incertezas em relação a seu estado de saúde, investigação médica ou exigência do parceiro. 
Vim pra tirar uma dúvida, percebi algo esquisito, mas tô bem acho que é só um HPV (U08).

Tá sendo "de boa". Vim pra fazer porque tô fazendo uma cadeira na faculdade de medicina, de infectologia, e me vi estudando várias doenças, sendo nunca fiz nenhum teste pra saber se tenho alguma, mesmo as vezes fazendo sexo desprotegido (U03).

Vim fazer o teste porque minha namorada me obrigou, mas no fim foi bom [...] (U07).

O temor e pavor diante do resultado fazem com que os usuários barganhem, façam promessas e acreditem num novo recomeço enquanto aguardam a 'sentença'.

[...] mas depois do resultado daqui vou mudar (U09).

[...] vim, tirar logo a dúvida, me livrar e ganhar minha segunda chance (risos) (U05).

[...] bom, porque nunca fiz, então vai ser tipo iniciar uma vida do zero (U07).

[...] a situação de vir fazer um exame que pode ser uma sentença, porque algumas doenças não tem cura. (U04).

O medo em realizar o exame promove no imaginário coletivo a crença de 'estou incluso em grupo de risco, conforme evidenciado nos depoimentos:

Olha, tá sendo muito difícil, porque pra eu vir aqui é porque realmente estou em risco, me expus em uma situação bem arriscada, tive relações com uma pessoa que além de ter um relacionamento com outro homem, ele também usa drogas, sabe? (U15).

Percepções antagônicas de tranquilidade-traição, medo da morte, da incurabilidade e do diagnóstico, especialmente do HIV, medo de estar doente e, ainda, atenuação da culpa relativa à transmissão, necessidade de diagnóstico e de início do tratamento precocemente são fatores que, em geral, motivam pacientes e parceiros a buscarem atendimento. ${ }^{17}$ Baseado nessa ótica, a percepção dos usuários sobre o TR é descrita como convite para repensar as práticas, o que requer compreender as necessidades manifestas por estes e, consequentemente, aproximar o serviço centrado nas respostas humanas. ${ }^{18}$

Neste momento, a partir das falas dos usuários, observa-se que o medo de uma descoberta positiva no TR age como figura na percepção destes, ou seja, enquanto elemento principal, que Merleau-Ponty esclarece:

Uma "figura" sobre um "fundo" já contém, dissemos muito mais do que as qualidades atualmente dadas. Ela tem "contornos" que não "pertencem" ao fundo e se "desprendem" dele, ela é "estável" e de cor "compacta", o fundo é ilimitado e de cor incerta, ele "continua" sob a figura ${ }^{16: 38}$.
Esta passagem revela que o medo do resultado se mostra enquanto figura na percepção dos usuários, e o fundo contém incertezas e formas de subjetivação que se dão a partir de uma doença carregada de estigmas que, apesar de configurar um convite a novas práticas, pode vir como uma forma de culpabilização do usuário e condenação de seu estilo de vida.

O campo da percepção sobre o TR traz um conjunto de essências que denotam os distintos e mais variados sentidos das vivências do grupo de pessoas que participaram do aconselhamento coletivo.

\section{Intencionalidade de sentimentos}

Esta categoria apresenta os sentimentos dos usuários em relação à expectativa de realizarem o TR. Merleau-Ponty ${ }^{16}$ desenvolve o conceito de intencionalidade ao diferenciá-la da visão anteriormente apresentada por Franz Brentano e Edmund Husserl e ao afirmar que a intencionalidade não se manifesta enquanto um absolutismo da consciência, mas enquanto uma intencionalidade que se desvela como condição de possibilidade sob um fundo opaco, ou seja, que se desenvolve a partir do momento que é pré-reflexiva por excelência. ${ }^{19}$

Sob a intencionalidade de ato ou tética, e como sua condição de possibilidade, encontrávamos uma intencionalidade operante, já trabalhando antes de qualquer tese ou qualquer juízo, um "Logos do mundo estético", uma "arte escondida nas profundezas da alma humana", e que, como toda arte, só se conhece em seus resultados $^{19: 575}$.

Constatamos que são muitos os sentimentos envolvidos que antecedem o TR, destacando-se: tensão, desespero, incerteza, medo, ansiedade, arrependimento, raiva, preconceito e nervosismo, conforme depoimentos.

Tô tenso, esperando esse resultado! Bate um desespero essa dúvida (U01).

Angustia, a gente tem medo de fazer e não ser o resultado que esperamos (U02).

Quando vim começou a bater uma ansiedade, comecei a rever minhas atitudes, e possíveis contaminações, aí deu um medo, uma angustia (U03).

Medo, medo de tudo, medo do diagnóstico, medo de não poder mais ser mãe de novo, que é meu maior sonho, medo de não poder tá com minha filha, medo do preconceito (choro) (U06).

Nervoso, mas acho que tá tudo bem (U12).

O medo e a curiosidade despontam como os sentimentos mais prevalentes durante $o$ aconselhamento coletivo. $O$ conceito de intencionalidade se mostra ao considerarmos as diferentes manifestações emocionais presentes nas entrevistas. Tal fato denota a importância da orientação singular centrada no apoio emocional, cujos sentimentos de medo e recusa pelo teste encontram-se sedimentados em informações infundadas e distorcidas representadas pela sociedade a respeito de IST/HIV/Aids. ${ }^{20}$ 
Alguns usuários conseguem pensar nas consequências quando se veem diante do diagnóstico em relação ao futuro. Tal fato potencializa os sentimentos negativos.

Ansiedade, não posso mentir, que um pouco de medo também, mas tô preparada "pro que vier" (U09).

[...] não sei o que esperar do resultado e não sei como será minha vida se for positivo (U11).

A calmaria ou tentativa de manter-se calmo faz parte do discurso de U08.

Tô tranquilo, calmo, a gente fica apreensivo, mas tô tentando me manter calmo (U08).

Quando a calma não se faz presente, altera-se a percepção de tempo conforme US10 relata.

[...] nunca esses 30 minutos passaram "tãooooo" devagar (U10).

Os sentimentos vivenciados por usuários de serviços de saúde, enquanto aguardam atendimento médico ou resultado de exames, interferem de maneira significativa na qualidade do serviço e na percepção do tempo do usuário. A experiência do tempo tem papel fundamental para a constituição da subjetividade, bem como para o engajamento ambíguo do homem ao mundo. Ela pode ser compreendida por meio de dois aspectos: no primeiro, deparamo-nos com o tempo objetivo, responsável pela contagem das horas e que auxilia na organização concreta do mundo; no segundo, encontramos o tempo vivido, pessoal e de ordem subjetiva, que se atrela à singularidade das experiências. O movimento contínuo e sempre em fluxo presente em ambos os modos experienciais do tempo é destacado por Merleau-Ponty ${ }^{16}$ como temporalidade.

A experiência de temporalidade, portanto, pode se manifestar por duas dimensões distintas: dimensão real, que consiste na espera efetiva e; dimensão percebida, que se encontra imbricada como este experienciou a passagem do tempo. ${ }^{21}$

As explicações durante $o$ aconselhamento coletivo pelos profissionais foram ao encontro dos anseios dos usuários, minimizando-as, confortando-os, acalmando-os, sanando dúvidas sobre IST e práticas sexuais, gerando novos conhecimentos e, assim, emergindo novos sentimentos, dúvidas e/ou inquietações enquanto aguardavam o resultado.

A mulher (enfermeira) [...] foi explicando as coisas [...] 0 que ia acontecer e foi falando das doenças, isso foi me deixando mais tranquilo (U01).

Me senti mais calma, mas também porque prestei atenção na aula e esqueci um pouco do teste (risos). Mas foi bom, ela falou várias coisas que eu não sabia (U02).

Até que me acalmou mais, ela fala parece que tá falando com uma amiga, bem tranquila e segura. Ensinou várias coisas e também orientou como a gente se prevenir (U04).
O recebimento de grande quantidade de informações e de assuntos considerados tabus, abordados em curto intervalo de tempo, num espaço coletivo, somados à tensão e apreensão do diagnóstico e receio do outro, promovem novos sentimentos e bloqueiam aqueles que não se sentem confortáveis diante de desconhecidos.

A intersubjetividade no aconselhamento se mostra nas entrevistas quando, como visto por (U01), os profissionais elaboram um processo de coexistência com os usuários, ou seja, quando se colocam na relação de forma ambígua, reconhecendo-se no outro e no mundo vivido por ele, e quando auxiliam no reconhecimento de assuntos que também permeiam o universo de ambos.

Acho que essa aula deveria ser dada para pessoas que tem um pré-diagnóstico, porque essas doenças e figuras assustam (U08).

Vendo tudo ali, bateu um medo, ver que a gente pode pegar tanta coisa, então bateu um nervoso, um medo de ter e não saber, mas ela foi muito boa, explicou tudo (U11).

Pode-se compreender, assim, que os sentidos e sentimentos intencionais são impulsos idiossincráticos que marcam a significação do fazer o TR no contexto HIV/aids, e que há maneiras distintas em experienciar o fenômeno. A multiplicidade de sentimentos, até aqui desvelados, evidencia a necessidade de desenvolver cuidados diversos, promovendo a valorização da subjetividade humana, que devem ir ao encontro da real necessidade e do sofrimento experienciado pelo usuário no teste rápido, uma vez que a construção de significados é particular.

\section{Percepção do aconselhamento pelo usuário}

Nesta categoria, os usuários apresentam, em alguns momentos, percepções divergentes e convergentes, atribuindo sentidos e significados sobre o que é aconselhamento e acolhimento durante o contexto de TR.

Não demorou, foi rápido, os profissionais foram acolhedores, me senti abraçada, pois no fim, uma especificamente perguntou pra mim se eu tava bem (U11).

É bom estar ao lado de outras pessoas na mesma situação que eu, isso tranquiliza (U01).

As notas emitidas pelos usuários sobre percepção de aconselhamento e acolhimento se associam às ideias de respeito, estima, solicitude e reconhecimento, mas também à noção de cuidado - atenção a si e ao outro. Assim, temos a fenomenologia do cuidar compreendida entre a atitude de acolher e a cumplicidade com o outro, desvendando o sentido das manifestações existenciais presentes na condição humana.

Diferentemente, os outros usuários não se sentiram ou não se perceberam aconselhados e/ou acolhidos durante a prática coletiva. 
Achei bem interessante, mas não acho que foi aconselhamento foi uma aula, bem explicativa, que atinge todas pessoas, onde é falado de práticas sexuais e as doenças (U03).

Acolhido? Só cheguei, peguei a senha, esperei a palestra, fiz o exame e to aqui esperando o resultado. Acho que ela vai falar melhor comigo quando for me dar o resultado (U05).

Teve só a palestra né, mas foi boa, ela mostrou algumas coisas, acalmou, falou que existe tratamento de algumas doenças e que dá pra viver Eu não sei se tem o aconselhamento, porque entendo que isso deveria ser uma conversa individual, pra ela ouvir meus problemas, mas eu gostei me ajudou, mesmo que só me explicando as coisas. (U06).

Aconselhamento coletivo é percebido pelos usuários como aula/palestra sobre IST/Aids, com emprego de linguagem acessível aos mais diversos níveis de compreensão (letramento funcional), recursos visuais atrativos e ênfase em consequências negativas e postura das facilitadoras.

Aprendi bastante na aula [...] (U02).

[...] explica em uma linguagem bem fácil de ser entendida, é bem educativo [...] (U03).

A doutora explicou bem, ensinou umas coisas, aprend bastante (U04).

Gostei muito, aprendi bastante, e vou tentar colocar em prática o que ela ensinou (U07).

A palestra foi boa, eles explicam, mostram figuras, tiram dúvidas, falam de práticas sexuais, percebo que se preocupam em explicar bem (U08).

A percepção sobre aconselhamento e acolhimento, para os usuários, tem início com o acolhimento do usuário ao serviço de saúde, que é estabelecido no diálogo e na relação de confiança, com vistas ao empoderamento do sujeito sobre suas condições saúde. Dessa forma, o significado atribuído por estes concorda com a filosofia preconizada pelo MS. As narrativas exprimem proposições como: aproximar-se de, estar com, importar-se com. Logo, desvela a definição do conceito de aconselhamento.

Em pesquisa realizada anteriormente no município de Fortaleza, cujo objetivo foi de conhecer a percepção dos usuários acerca do componente informativo do aconselhamento pré-teste, estes compreenderam o aconselhamento como atividade de cunho educativo com a finalidade de privilegiar conteúdos informativos e normativos em relação à prevenção das IST e do HIV/Aids. ${ }^{21}$ Autore ${ }^{22}$ criticam a metodologia utilizada para facilitar a aquisição dessas informações por esta adotar prática verticalizada, isto é, o profissional detém todo o conhecimento sobre o assunto e o usuário participa apenas passivamente. Assim, o aconselhamento não se comporta como diálogo entre profissional e usuário, e, com isso, não se emprega o princípio da integralidade do ser humano e muito menos se promove cuidados, restringindo-se a prática somente ao repasse de informações.

As informações, quando realizadas por meio de discussão com os usuários, promovem reflexão sobre as situações de risco/vulnerabilidade deles e, consequentemente, mudanças processuais. Logo, o aconselhamento promove a capacidade de orientar as pessoas para que haja um maior envolvimento na prática do autocuidado, situação bastante complexa, mas que necessita de apoio constante dos serviços para se efetivar. ${ }^{23}$

A intersubjetividade, como já abordada, permeia as relações dos profissionais que aconselham e dos usuários que são orientados. A lente ambígua em Merleau-Ponty ${ }^{16}$ nos mostra que, apesar de lidarmos com elementos subjetivos, estes estão sempre envoltos pelo caráter da objetividade, estando ligados sempre a um caráter social.

Assim, compreendemos um caráter de entrelaçamento do processo de aconselhamento ligado, segundo Merleau-Ponty, a uma radicalização da intersubjetividade para um processo carnal, em que os corpos se encontram em ambiguidade constante, não só estando no mundo, mas fazendo parte dele.

\section{Percepção do aconselhamento individual no pós-teste}

O aconselhamento bem conduzido e centrado nas reais necessidades apresentadas pelo usuário contribuiu com a expressão de atitudes positivas em relação às práticas sexuais no futuro. Tal fato encontra-se firmado pela qualidade deste no pré-teste e pela oferta de apoio emocional para o enfrentamento do possível resultado.

No individual ela explicou, conversou mais comigo, me tranquilizou um pouco, e me deu o resultado [...] foi rápida, ela faz algumas perguntas, fala mais um pouco das doenças e diz que todas as pessoas devem usar camisinha, independentemente de serem casadas ou não (U13).

[...] no individual, ela fez mais perguntas, perguntou algumas coisas sobre sexo, e me deu o resultado. Gostei, mas só em entrar na sala, a gente tá começa a tremer (U14).

[...] o individual foi bom também, ela tirou algumas dúvidas, que fiquei com vergonha de perguntar no coletivo e orientou muito o uso do preservativo (U15).

O aconselhamento pós-teste representa o momento de entrega do exame anti-HIV e é muito mais carregado de tensão e ansiedade que a solicitação do teste (pré-teste), pois representa o momento real de descoberta ou não da soropositividade. Normalmente, é a ocasião em que a pessoa reflete acerca dos riscos vivenciados e da possibilidade de portar o HIV. Quando ocorre bom aconselhamento no pré-teste, verifica-se, como consequência, melhor engajamento e adesão ao tratamento e autocuidado de pessoas que obtiveram teste positivo, ${ }^{23}$ o que nos remete, novamente, à importância da noção da intersubjetividade e da coexistência nos processos de aconselhamento. 
Um dos objetivos essenciais desta etapa é apoiar o(a) usuário(a), que vivencia situações de risco, no fortalecimento de práticas mais seguras para não se infectarem, ou na adesão ao tratamento no caso de resultado reagente. Para tanto, o serviço ou o projeto de base comunitária deve ter uma equipe com profissionais de saúde preparados para realizar a entrega do resultado, bem como oferecer aconselhamento e fazer os encaminhamentos necessários. Portanto, é necessário conhecer o fluxo de serviços de saúde da região. ${ }^{24}$

$\mathrm{O}$ aconselhamento pós-teste é relevante porque, em caso de resultado negativo, pode estimular a mudança de comportamentos preventivos relacionados à infecção do HIV e, em caso de resultado positivo, pode ajudar com o potencial de transmissão e iniciar o tratamento antirretroviral o mais breve possível. ${ }^{24} \mathrm{O}$ aconselhamento é uma etapa fundamental no processo de testagem, pois constitui uma ferramenta para reflexão e tomada de decisão conjunta.

Neste contexto, Merhy ${ }^{25}$ atenta para a utilização das tecnologias leves ou relacionais, ou seja, aquelas que só têm materialidade em ato. Destaca-se, desse modo, as relações de entrelaçamento no ato do aconselhamento ou, como abordadas por Merleau-Ponty a partir do caráter ambíguo de sua filosofia, aquelas caracterizadas por um campo aberto por meio da qual se desencadeia a experiência de coexistência. ${ }^{16}$

\section{Percepção dos profissionais sobre o aconselhamento}

Neste ensaio, foi dada voz aos profissionais para que transcendessem o campo prático, passando a falar do significado do modo de atuação como instrumento de relação com o mundo e, a partir de experiências vividas, complementar a análise do fenômeno em estudo. Portanto, aqui é apresentada a visão de atores que influenciam, de maneira direta ou indireta, a percepção dos usuários partindo de posição vertical, contínua, do outro lado do caleidoscópio. Trata-se de abordar o fenômeno em suas múltiplas facetas.

Os profissionais envolvidos no aconselhamento coletivo percebem como ferramenta fundamental a escuta qualificada. Compreendem, inclusive, que os usuários estão inseridos em contextos socioculturais particulares e não dissociáveis de sua experiência vivida. Sendo, as informações repassadas, fundamentais para prepara-los para as diversas possibilidades diagnósticas.

Acredito ser a ferramenta mais importante do serviço, é fundamental. Pois a intenção é uma escuta qualificada para compreender o indivíduo e ter uma abordagem especifica (P01).

[...] uma das ferramentas mais importantes do serviço, pois as informações que damos aos pacientes é fundamental (P02).

Percebo como um grande aprendizado, aqui eles podem fazer perguntas, tirar o medo, não serão julgados por suas condutas, um local seguro e aberto (P03).
[...] percebemos [...] que quando o paciente chega mais tarde e não faz o aconselhamento ele sente falta, vai fazer a coleta e receber o resultado ainda mais inseguro e fragilizado (P04).

Os profissionais são unanimes em relação à função do aconselhamento. Para eles, é incumbência educativa.

Questão educativa, sendo a pratica de fazer menos perguntas e dar mais respostas. A missão do CTA deveria ser o aconselhamento, pois sana as dúvidas de todos, diminui a ansiedade e a angustia. É uma educação em saúde dando orientação, diminuindo assim o preconceito e a culpa (P05).

Educativa, nos falamos de todas as ISTs, tentamos sensibilizar para assim eles tenham uma mudança de comportamento e assim consigam se prevenir (P02).

Esclarecemos o que será realizado, falamos sobre IST's, munimos os pacientes de informações, e assim eles podem divulgar também essas informações (P03).

Os depoimentos dados pelos profissionais vão ao encontro da pesquisa realizada em Minas Gerais, cuja percepção dos profissionais sobre aconselhamento é reduzida simplesmente a orientar o usuário para minimização dos riscos de determinada doença, sendo, porém, considerada prática relevante..$^{26,27}$

O fazer aconselhamento no pré-teste é compreendido pelos profissionais como atividade adorável, diferencial, modificadora/ promotora de mudanças, pois gera conhecimento novo.

[...] uma das melhores coisas, pois consigo sensibilizar e assim mostro que a responsabilidade é múltipla, tento assim fazer a pessoa se perceber, e ela se perceber se está em uma situação de risco. Fico feliz quando a pessoa tem coragem de revelar coisas tão intimas como sua prática sexual pra mim, sinal de confiança, e assim posso ser um agente transformador, além empoderá-la também com informações para que ela possa ser um multiplicador da informação (P01).

Eu gosto bastante, sempre tento modificar, pra não ser igual, para ser mais "a cara do grupo", mesmo sendo bem diversificado o público. Acho uma pena quando alguém não pode assistir (P03).

Eu adoro. Acho que ajuda muito, e se percebo alguma pessoa mais aflita chamo pra conversar, principalmente na hora da entrega do resultado, por ser individual (P04).

Eu gosto de fazer porque eles ficam mais cientes quando fazem o teste. Acho importante dar esse conhecimento, e assim podem se prevenir melhor e saber os riscos (P05).

Por meio das narrativas, observa-se que o aconselhamento pelo profissional se encontra sedimentado na sensibilização, avaliação de riscos e apoio emocional ao usuário. 
A prática do aconselhamento deve transcender as orientações de prevenção e promoção da saúde, pois necessita abordar os medos relacionados à comunicação do diagnóstico de IST a si e ao parceiro. Além disso, é preciso reconhecer o potencial de dano psicológico, físico e sexual em resposta à divulgação do diagnóstico. ${ }^{28}$

Os profissionais revelam uma linha no que concerne formação/preparação para realizar prática do aconselhamento coletivo. Com exceção do P01, os demais aprenderam a apreender, observando, reproduzindo e adaptando o realizado por outros profissionais no serviço.

[...] aprendi no próprio setor, no dia-a-dia (P02).

[...] estou só há 3 meses aqui, então fui aprendendo vendo as colegas, assistia o que elas ministravam e fui "pegando" (P03).

[...] aprendi na prática, acertando, errado, o que vi uma colega fazendo que dava certo, implementava (P04).

[...] aprendi com as outras, assistindo quando elas realizavam (P06).

A prática do aconselhamento por profissionais, seja construída por meio de desenvolvimento de habilidades distintas (cognitivas, atitudinais, comunicativas), competências em treinamento, educação continuada e readequações na rotina do serviço, objetiva legitimar os princípios doutrinários e organizacionais que regem o SUS. ${ }^{29}$

Um aspecto observado e relatado informalmente pelos entrevistados foi no aconselhamento pós-teste, principalmente quando o resultado é positivo. Esse diagnóstico costuma impactar tanto a pessoa quanto o profissional. Portanto, é fundamental que o profissional esteja preparado para oferecer apoio emocional, respeitando, é claro, o tempo do paciente e a reação dele diante do resultado. Assim sendo, independentemente de um resultado negativo, positivo ou indeterminado, o profissional necessita ser capacitado para realizar a abordagem adequada.$^{30} \mathrm{Vale} \mathrm{ressaltar}$ ainda a importância da elaboração e implementação de projetos de educação permanentes.

Independentemente da situação, o aconselhamento é uma etapa privilegiada para ações educativas de acolhimento, ensinamento e esclarecimento. No entanto, estudos evidenciam que os profissionais de saúde necessitam ser capacitados, inclusive em serviço, para ações de aconselhamento e manejo clínico. Nesse sentido, é importante que a pessoa que realiza o teste rápido e $\mathrm{o}$ aconselhamento seja detentor de conhecimento atualizado, com reciclagem periódica sobre DST, HIV e aids. A qualificação para os profissionais que atuam nas UBS pode ser realizada por meio de capacitação presencial e/ou a distância. Além disso, os profissionais devem ter suporte de colegas com maior experiência em questões relacionadas à infecção por HIV e aids. ${ }^{31}$

Pode-se identificar que alguns aspectos das entrevistas se destacaram, como: experiência anterior à realização do TR, em que a tomada da consciência realizou-se por meio da experiência eu-no-mundo; a intencionalidade de sentimentos, sedimentada em sentidos e afetos intencionais no modo de experienciar o fenômeno, mediante ressignificações a partir de percepções das vivências do usuário, e o que convergiu e/ou divergiu na percepção sobre aconselhamento e acolhimento pelo usuário investigação sobre a percepção do aconselhamento individual no pós-teste e a percepção do profissional sobre o aconselhamento, que foram reveladas em linha tênue concernente ao processo de capacitação.

\section{CONCLUSÕES E IMPLICAÇÕES PARA A PRÁTICA}

A manifestação do fenômeno aqui estudado possibilitou melhor apreensão, compreensão e percepção dos significados e sentidos atribuídos aos usuários que buscam o TR no contexto HIV/Aids, bem como o melhor atendimento deste. Logo, faz-se necessário que o usuário seja aconselhado e se sinta acolhido pelos profissionais que realizam o aconselhamento coletivo. Ademais, esses profissionais devem proporcionar apoio emocional adequado com vistas à garantia da continuidade do tratamento.

Foi compreendido que o aconselhamento, principalmente o coletivo, é percebido pelos usuários como aula/palestra sobre IST/Aids, que emprega uma linguagem acessível aos mais diversos níveis de compreensão (letramento funcional), que se utiliza de recursos visuais atrativos, dando ênfase às consequências negativas e à postura das facilitadoras. Já em relação ao aconselhamento individual, diferentemente do coletivo, os usuários se sentiram mais confortáveis em realizar perguntas e expor suas dúvidas. Convergindo na mesma direção, na compreensão dos profissionais, mesmo sabendo da importância do aconselhamento, estes realizam a prática de forma empírica, reduzindo o ato ao repasse de informações com teor educativo, visando que o usuário aprenda e seja disseminador do conhecimento, tentando assim reduzir a cadeia de transmissão da IST/Aids.

Ressalte-se, contudo, que os resultados aqui apresentados se apoiam na análise de um número restrito de casos que constituíram a amostra desta pesquisa. Fica evidenciada a necessidade de mais estudos sobre a temática, com envolvimento de usuários, parceiros e todos os profissionais de saúde envolvidos no contexto, para melhor compreensão do contexto/realidade e garantia de cuidado integral e contínuo, não restrito a um momento pontual como este estudo.

Espera-se que esta pesquisa contribua para a melhoria da gestão dos cuidados de saúde e para o aperfeiçoamento e reflexão dos profissionais da área da saúde, especialmente os envolvidos na prática do aconselhamento, que lidam diretamente com o cuidado e têm a responsabilidade de educar/informar/esclarecer/aconselhar/acolher o usuário em suas dúvidas e angústias relacionadas às IST/HIV/Aids. Pretende-se também que os gestores possam implementar políticas públicas efetivas para atender com qualidade essa clientela, de modo a oferecer condições de trabalho à equipe multiprofissional que atende o usuário em risco. 


\section{CONTRIBUIÇÕES DOS AUTORES}

Concepção e desenho do estudo. Coleta, análise e interpretação dos dados. Discussão dos resultados. Redação e revisão crítica do manuscrito. Aprovação da versão final do artigo. Responsabilidade por todos os aspectos do conteúdo e a integridade do artigo publicado: Paula Barreto Silva Xenofonte Costa Lima. Análise e interpretação dos dados. Discussão dos resultados. Redação e revisão crítica do manuscrito. Aprovação da versão final do artigo. Responsabilidade por todos os aspectos do conteúdo e a integridade do artigo publicado: Maria Alix Leite Araújo Anna Karynne Melo João Marcos de Araújo Leite.

\section{EDITOR ASSOCIADO}

\section{Stela Maris de Mello Padoin}

\section{REFERÊNCIAS}

1. Ministério da Saúde (BR). HIV Aids 2018. Brasília: Ministério da Saúde; 2018. 72 p. (Boletim Epidemiológico).

2. World Health Organization. HIV/Aids [Internet]. Genebra: WHO; 2019 [citado 2019 Out 9]. Disponível em: https://www.who.int/gho/hiv/en/

3. Ha JH, Van Lith LM, Mallalieu EC, Chidassicua J, Pinho MD, Devos P et al. Gendered relationship between HIV stigma and HIV testing among men and women in Mozambique: a cross-sectional study to inform a stigma reduction and male-targeted HIV testing intervention. BMJ Open. 2019 out;9(10):e029748. http://dx.doi.org/10.1136/bmjopen-2019-029748. PMid:31594877.

4. Alexandra Marshall S, Brewington KM, Kathryn Allison M, Haynes TF, Zaller ND. Measuring HIV-related stigma among healthcare providers: a systematic review. Aids Care. 2017 nov;29(11):1337-45. http://dx.doi. org/10.1080/09540121.2017.1338654. PMid:28599599.

5. Marques HH, Silva NG, Gutierrez PL, Lacerda R, Ayres JRCM, Della Negra $M$ et al. A revelação do diagnóstico na perspectiva dos adolescentes vivendo com HIV/Aids e seus pais e cuidadores. Cad Saude Publica. 2006;22(3):619-29. http://dx.doi.org/10.1590/S0102311X2006000300017. PMid:16583106

6. Poirier C, Aymeric S, Grammatico-Guillon L, Lebeau JP, Bernard L, Le Bret $P$ et al. Rapid HIV test in family practice. Med Mal Infect. 2015 jun;45(6):207-14. http://dx.doi.org/10.1016/j.medmal.2015.03.010. PMid:25982343.

7. Telles-Dias PR, Westman S, Fernandez AE, Sanchez M. Perceptions of HIV rapid testing among injecting drug users in Brazil. Rev Saude Publica. 2007;41(Supl 2):94-100. http://dx.doi.org/10.1590/S003489102007000900015. PMid:18094792.

8. Ferreira AD, Caiaffa WT, Bastos FI, Mingoti SA. Profile of male Brazilian injecting drug users who have sex with men. Cad Saude Publica. 2006;22(4):849-60. http://dx.doi.org/10.1590/S0102-311X2006000400023. PMid:16612438.

9. Ministério da Saúde (BR). Aconselhamento e DST/HIV/Aids para atenção básica. Brasília: Ministério da Saúde; 2003.

10. Vilela MP, Brito TRB, Goyatá SLT, Arantes CIS. Perfil epidemiológico dos usuários do Centro de Testagem e Aconselhamento de Alfenas, Minas Gerais. Rev Eletr Enf. 2010;12(2):327-30. http://dx.doi.org/10.5216/ree. v12i2.5200

11. Grangeiro A, Escuder MM, Wolffenbuttel K, Pupo LR, Nemes MI, Monteiro $\mathrm{PH}$. Technological profile assessment of voluntary HIV counseling and testing centers in Brazil. Rev Saude Publica. 2009;43(3):427-36. http:// dx.doi.org/10.1590/S0034-89102009000300006. PMid:19448912.

12. Minayo MCS. Pesquisa social: teoria, método e criatividade. 29. ed. Petrópolis: Vozes; 2010.
13. Giorgi A. Phenomenology and psychological research. Pittsburg: Duquesne University Press; 1985.

14. Giorgi A. Phenomenological psychology. In: Willig C, StaintonRogers W, editores. The SAGE handbook of qualitative research in psychology: grounded theory. London: Sage;2008. p. 3-29. http://dx.doi. org/10.4135/9781848607927.n10.

15. Husserl E. The idea of phenomenology. The Hague: Martinus Nijhoff; 1964.

16. Merleau-Ponty M. Fenomenologia da percepção. 4. ed. São Paulo: Martins Fontes; 2011.

17. Araújo MAL, Rocha AFB, Cavalcante EGF, Moura HJ, Galvão MTG, Lopes ACMU. Doenças sexualmente transmissíveis atendidas em unidade primária de saúde no Nordeste do Brasil. Cad Saude Colet. 2015;23(4):347-53. http://dx.doi.org/10.1590/1414-462X201500040051.

18. Carvalho FT, Both NS, Alnoch EM, Conz J, Rocha KB. Counselling in STD/HIV/Aids in the context of rapid tests: Perceptions of users and health professionals at a counselling and testing centre in Porto Alegre. J Health Psychol. 2016;21(3):379-89. http://dx.doi.org/10.1177/1359105316628741. PMid:26987832.

19. Castro TG, Gomes WB. Fenomenologia e psicologia experimental no início do século XX. Psicol, Teor Pesqui. 2015set;31(3):403-10. http:// dx.doi.org/10.1590/0102-37722015032125403410.

20. Barroso LMM, Soares AP, Soares BC, Araújo MAL, Silva DMA Percepção dos usuários acerca do aconselhamento pré-teste anti HIV em uma unidade de referência em Fortaleza, Ceará. Espaç Saúde. 2010;12(1):23-9.

21. Barbosa TLA, Gomes LMX, Holzmann APF, Paula AMB, Haikal DSA. Aconselhamento em doenças sexualmente transmissíveis na atenção primária: percepção e prática profissional. Acta Paul Enferm. 2015;28(6):531-8. http://dx.doi.org/10.1590/1982-0194201500089.

22. Taquette SR, Rodrigues AO, Bortolotti LR. Percepção de pacientes com Aids diagnosticada na adolescência sobre o aconselhamento pré e pós-teste HIV realizado. Ciênc. Saúde Coletiva. 2017;22(1):23-30. http://dx.doi.org/10.1590/1413-81232017221.23532015.

23. Parucker LMBB, Franz HCF, Pires AFNPC, Soares DC, Alonso No JB , Martins MV et al. Infecções sexualmente transmissíveis: cuidados na execução dos testes rápidos: módulo II: orientações pré e pós. Florianópolis: ACL/UFSC; 2017.

24. Ministério da Saúde (BR). HIV/aids, hepatite e outras DST's. Brasília: Ministério da Saúde; 2006. (Cadernos de Atenção Básica).

25. Merhy E. Saúde: a cartografia do trabalho vivo. São Paulo: Hucitec 2002.

26. Bailey $\mathrm{H}$, Zash R, Rasi V, Thorne C. HIV treatment in pregnancy. Lancet HIV. 2018Aug;5(8):e457-67. http://dx.doi.org/10.1016/S23523018(18)30059-6. PMid:29958853.

27. Flores TR, Gomes AP, Soares ALG, Nunes BP, Assunção MCF, Gonçalves $\mathrm{H}$ et al. Aconselhamento por profissionais de saúde e comportamentos saudáveis entre idosos: estudo de base populacional em Pelotas, sul do Brasil, 2014. Epidemiol Serv Saude. 2018;27(1):e201720112. http:// dx.doi.org/10.5123/S1679-49742018000100012. PMid:29451616.

28. Andrade RF, Araujo MA, Vieira LJ, Reis CB, Miranda AE. Intimate partner violence after the diagnosis of sexually transmitted diseases. Rev Saude Publica. 2015;49(3):1-9. http://dx.doi.org/10.1590/S00348910.2015049005424. PMid:25741656.

29. Mora C, Monteiro S, Moreira COF. Formação, práticas e trajetórias de aconselhadores de centros de testagem anti HIV do Rio de Janeiro, Brasil. Interface. 2015;19(55):1145-56. http://dx.doi.org/10.1590/180757622014.0609.

30. Rocha KB, Santos RRG, Conz J, Silveira ACT. Network transversality: matrix support in the decentralization of counseling and rapid testing for HIV, syphilis, and hepatitis. Saúde Debate. 2016;40(109):22-33. http://dx.doi.org/10.1590/0103-1104201610902.

31. Araújo WJ, Quirino EMB, Pinho CM, Andrade MS. Perception of nurses who perform rapid tests in Health Centers. Rev Bras Enferm 2018;71(Supl 1):631-6. http://dx.doi.org/10.1590/0034-7167-2017-0298. PMid:29562021. 